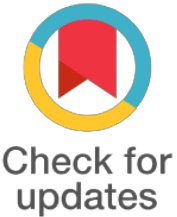

updates
*For correspondence:

dotrungkienbio@gmail.com

Competing interests: The authors declare that no competing interests exist.

Received: 2017-07-01

Accepted: 2017-08-03

Published: 2017-09-05

Copyright The Author(s) 2017. This article is published with open access by BioMedPress (BMP).

This article is distributed under the terms of the Creative

Commons Attribution License (CC-BY 4.0) which permits any use, distribution, and

reproduction in any medium, provided the original author(s) and the source are credited.

PORTER

\title{
Effect of fluorescent nanodiamonds on umbilical cord mesenchymal stem cell differentiation into hepatocyte-like cell
}

\author{
Trung Kien Do, Nguyen Thi Thanh Nga, Nguyen Quynh Anh, Dinh Minh Pham, \\ Chu Hoang $\mathrm{Ha}$
}

Institute of Biotechnology, Vietnam Academy of Science and Technology, Hanoi, Vietnam

\section{Abstract}

Fluorescent nanodiamond (FND) indicated that it has excellent biocompatibility and photostability, so it well suited for long-term labeling and tracking of stem cells. There are many reports concerning the factors controlling stem cell differentiation. However, still little knowledge about the biomaterials properties influence stem cell alive, growth and differentiation processing. In this study, we evaluate the effect of fluorescent nanodiamond in in vitro culture and differentiation of ucMSC into hepatocyte-like cell. Mesenchymal stem cells (MSCs) were isolated from the umbilical cord (UC) and $C D$ markers were analyzed by flow cytometry and genes expression. For hepatic differentiation of UC-MSCs, cells were induced with HGF and DMSO treated. FND was supply in

the experimental group which $10^{\circ} \mathrm{g} / \mathrm{ml}$ in 4 hours. The FND uptake was detected of fluorescence intensity of FND in cells by flow cytometry and laser scan microscopy. The effect of FND into UCMSCs was not only evaluated by the cell alive and growth assay but also effective differentiation throughout morphology charging or gene expression levels of AFP, ALB, and HNF4 - were determined by RT-PCR and real-time PCR. The result showed that the FND was well uptake in UCMSCs. It was no affected into ability of the cell alive and growth. The existence of FNDs does not disturb the functions of UC-MSCs differentiation into hepatocyte-like cell. FND can be utilized for the labeling and tracking of UC-MSCs and hepatocyte-like cell in homing research.

\section{Keywords}

Fluorescent nanodiamond, Differentiation, Hepatocyte-like cell, In vitro culture. Umbilical cord stem cells

Funding

This study was funded from: "Study on the differentiation of hepatocytes from human and mouse stem cells ", code: VAST.LL.03 / 16-17.

References 